\title{
Comparison of weight in middle age, weight at 18 years, and weight change between, in predicting subsequent 14 year mortality and coronary events: Caerphilly Prospective Study
}

\author{
John W G Yarnell, Christopher C Patterson, Hugh F Thomas, Peter M Sweetnam
}

\begin{abstract}
Objective-The prevalence of obesity is increasing in many European countries and in the United States. This report examines the mortality and morbidity associated with being overweight and obese in the Caerphilly Prospective Study and the relative effects of weight in middle age and self reported weight at 18 years. Design-All men aged 45 to 59 years from the town of Caerphilly, South Wales and outlying villages were identified and 2512 men were examined for the first time between 1979 and 1983. Men were asked to recall their weight at 18 years of age (when the majority had been examined for National Service) so that weight then, weight at screening, and the difference could be related to their 14 year follow up from screening. A total of 2335 men could recall their weight at 18 years. By 14 years of follow up from screening 465 men had died and 382 had had coronary events.
\end{abstract}

Results-Mean body mass index in men who reported their weight at 18 years was $22.3($ SD 2.8$) \mathrm{kg} / \mathrm{m}^{2}$ and only 41 of these men $(1.8 \%)$ were classified as obese (index $\left.\geqslant 30 \mathrm{~kg} / \mathrm{m}^{2}\right)$. The index did not predict all cause mortality when examined by quintile. For major ischaemic heart disease (non-fatal or fatal ischaemic heart disease) the relative odds was $1.73(95 \% \mathrm{CI}$ $1.21,2.48)$ in the top fifth of the distribution (body mass index $\geqslant 24.2 \mathrm{~kg} / \mathrm{m}^{2}$ ) compared with the bottom fifth (body mass index $<20.1 \mathrm{~kg} / \mathrm{m}^{2}$ ). In men with an index $\geqslant 30 \mathrm{~kg} / \mathrm{m}^{2}$ however, the relative odds were $2.03(95 \%$ CI, $1.03,4.01)$ for all cause mortality and $2.17(95 \% \mathrm{CI}, 1.08,4.34)$ for major ischaemic heart disease, adjusted for age, smoking habit and social class. When men were recruited to the study, from 1979 to 1983; the mean body mass index had increased to 26.2 (SD 3.6), a mean increase of $3.9 \mathrm{~kg} / \mathrm{m}^{2}$ or $11.2 \mathrm{~kg}$; 299 men $(12.1 \%)$ were classified as obese and showed significantly increased relative odds of both all cause mortality (1.53 (95\% CI 1.14, 2.06) and major ischaemic heart disease (1.55 (95\% CI 1.13, 2.11)), adjusted for age, smoking habit and social class relative to the non-obese men. The effect of gain in weight from 18 years to recruitment was also examined; all cause mortality showed highest mortality in the fifth of the distribution who experienced weight loss or minimal weight gain. For major ischaemic heart disease an inconsistent, weak trend was shown, the relative odds rising to a maximum of $1.26(0.89$, 1.80 ) in the top fifth of weight gain compared with the bottom fifth. Weight gain showed strong associations with potential cardiovascular risk factors measured at recruitment; insulin, triglyceride, glucose, diastolic and systolic blood pressure and high density lipoproteincholesterol.

Conclusions-Body mass at 18 years of age of $30 \mathrm{~kg} / \mathrm{m}^{2}$ or more conferred increased risk for all cause mortality and major ischaemic heart disease during 14 years of follow up of men aged 45 to 59 years. By the baseline examination the prevalence of obesity (body mass index $\geqslant 30$ ) had increased from $1.8 \%$ to $12.1 \%$; obese men also showed an excess risk of major ischaemic heart disease and overall mortality, but these risks were lower than those predicted from 18 years of age. Weight gain was strongly associated with smoking habit, the greatest weight gain being among ex-smokers and the least among light smokers. Weight gain from 18 years of age to baseline examination showed little relation with subsequent mortality and risk of major ischaemic heart disease when adjusted for age, smoking habit and social class. The lowest mortality rate occurred in the "fifth" of men who gained a mean weight of $16.1 \mathrm{~kg}$. Weight gain is closely associated with some adverse cardiovascular risk factors; in particular with insulin, triglyceride, glucose and diastolic blood pressure.

(F Epidemiol Community Health 2000;54:344-348)

Obesity is increasing in younger populations ${ }^{1}$ but there is limited information available on its long term consequences. A recent report from the British Regional Heart Study ${ }^{2}$ suggested that the lowest mortality from any cause of death was found in the range for body mass index between $20.0-23.9 \mathrm{~kg} / \mathrm{m}^{2}$. Previous reviews ${ }^{3}{ }^{4}$ had suggested that a range of $20-27$ $\mathrm{kg} / \mathrm{m}^{2}$ showed no significant increase in risk of death in follow up studies. Others have suggested that morbidity associated with overweight should also be considered in determining ideal body weight. ${ }^{5}{ }^{6}$ This controversy has implications for public health, which is facing 


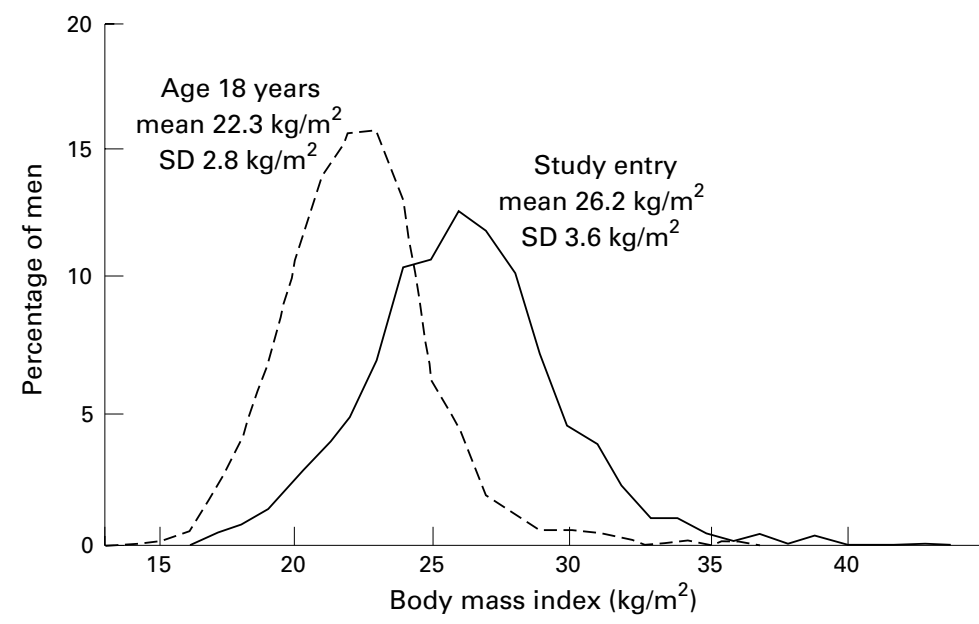

Figure 1 Distributions of body mass index at 18 years of age and at study entry (aged 45 to 59 years).
FOLLOW UP EXAMINATIONS

The results reported in this paper refer to the third follow up. This was at a nearly constant interval of almost 14 years (165 months (SD 6)).

At each follow up the Chest Pain Questionnaire was administered, and an electrocardiograph recorded. Details about hospitalisation for severe chest pain were also reported. These, together with Hospital Activity Analysis notifications of admissions coded as 410-414ischaemic heart disease in the 9th revision of the International Classification of Diseaseswere used as the basis for a search of hospital notes for events that satisfied the World Health Organisation criteria for definite acute myocardial infarction. ${ }^{9}$ For men who had died before the end of follow up, a copy of the death certificate was automatically received from the NHS Central Registers for England and Wales at Southport. From this information, three categories of incident coronary events were defined: coronary death, clinical non-fatal myocardial infarction and electrocardiographic myocardial infarction as previously described. ${ }^{9}$ A major coronary event was defined as one or more of the three possible outcomes described above.

\section{STATISTICAL METHODS}

Logistic regression analysis was used to compare the all cause mortality and ischaemic heart disease incidence during follow up in subgroups defined by body mass index, while adjusting for possible confounding variables.

Cardiovascular risk factors were compared in groups defined by quintiles of change in body mass index using one way analysis of variance. Tests for linear trend and departures from linear trend are reported. Changes in risk factor levels associated with each fifth increase in the index were rendered more comparable by expressing the coefficient for linear trend in terms of the standard deviation for each risk factor.

\section{Results}

A total of 2512 men were examined between 1979 and 1983; body mass index at recruitment was available for 2470 men. Approximately $7 \%$ of men could not recall their weight at 18 years (when the majority had been examined for National Service). Therefore self reported weight at 18 years was available for 2335 men, but often this was rounded to the nearest half stone. This was converted to kilograms. Quetelet's index was used as the standard measure of body mass (weight $/$ height $^{2}$ in $\left.\mathrm{kg} / \mathrm{m}^{2}\right)$.

Figure 1 shows the distribution of body mass index at 18 years. The mean value was 22.3 $\mathrm{kg} / \mathrm{m}^{2}$ (SD 2.8). Only 41 (1.8\%) men reported their weight as sufficient to be categorised as obese with an index of 30 or more $\mathrm{kg} / \mathrm{m}^{2}$. Figure 1 also shows the distribution of body mass index at recruitment with a mean value of 26.2 $\mathrm{kg} / \mathrm{m}^{2}$ (SD 3.6). This indicates an average increase in body mass of 3.9 units between the age of 18 years and recruitment (aged 45 to 59 years) an average weight gain of $11.2 \mathrm{~kg}$ (SD 


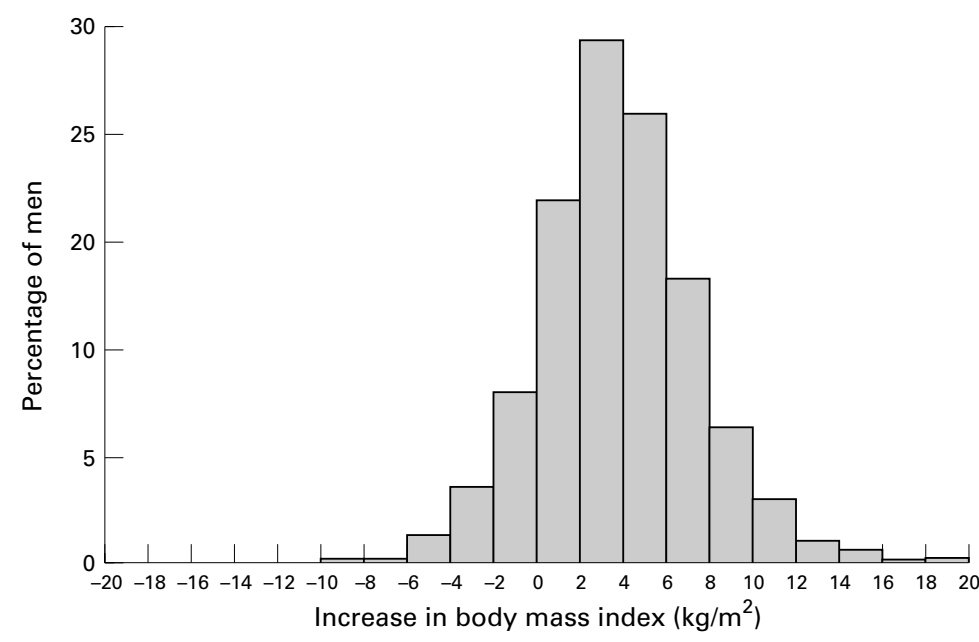

Figure 2 Distribution of change in body mass index in men from 18 years of age to study entry (aged 45 to 59 years).

11.2) but with a wide variation between men in the amount of weight gained. The Pearson correlation coefficient between weight at 18 years and recruitment was 0.48 . Figure 2 shows the distribution of the body mass change between the age of 18 years and recruitment. In all but 310 men $(13.3 \%)$ there is a gain in weight.

At 14 years 465 of the 2335 men with weight reported at 18 years had died and 382 had experienced a major coronary event (either fatal or non-fatal). Body mass index at 18 years of age did not significantly predict long term all cause mortality when examined by fifths of the distribution but the relative odds for incident ischaemic heart disease in the top fifth was 1.73 $(1.21,2.48)$ in comparison with the lowest fifth. This odds ratio is adjusted for age, smoking habit and social class; the last variable was included as two thirds of men were working or had been employed in heavy manual labour (table 1).

In Table 2 the small group classified as obese with a body mass index of 30 or more units at 18 years of age has been compared with the remainder of the population. The risk of subsequent mortality or of a coronary event was increased and statistically significant.
KEY POINTS

- Men who reported relative weight in the upper fifth of the distribution at 18 years of age experienced a $73 \%$ increase in the odds or risk of subsequent coronary disease from middle age ( 45 to 59 years) compared with men in the lowest fifth of the distribution, but a non-significant increase in death from any cause by 14 years of follow up.

- The very small group of men who were clinically obese at 18 years of age experienced double the risk of death from any cause or of subsequent coronary disease from middle age to 14 years of follow up.

- Weight gain by middle age showed no clear relation with risk of subsequent coronary disease and the lowest mortality from any cause was found in men who had gained $16.1 \mathrm{~kg}$ on average.

- Weight gain in men from youth to middle age is usual; substantial increases in weight are not associated with significantly increased mortality by 59 to 73 years of age in our cohort but are associated with increases in cardiovascular risk factors in middle age.

At recruitment $12.1 \%$ of this study population was obese. Among these men mortality was significantly increased by 1.53 (95\% CI $1.14,2.06)$ and risk of major ischaemic heart disease increased by 1.55 (95\% CI 1.13, 2.11).

The overall relation between weight at 18 years and at entry was weak $(r=0.34)$.

Table 3 shows the association between weight change from the age of 18 years to recruitment and subsequent mortality or incident ischaemic heart disease. The all cause mortality data show the highest mortality in those with minimal weight gain or weight loss. The relation between weight gain and mortality is curvilinear; the lowest mortality is experienced by the fifth of men gaining $16.1 \mathrm{~kg}$ on average. No clear pattern is evident for incident ischaemic heart disease.

Table 1 Risk of death or a coronary event in the 14 years after screening examination in fifths of the distribution of body mass index at 18 years of age

\begin{tabular}{|c|c|c|c|c|c|}
\hline $\begin{array}{l}\text { Body mass index } \\
\text { fifths }\left(\mathrm{kg} / \mathrm{m}^{2}\right)\end{array}$ & $\begin{array}{l}\text { Number } \\
\text { of men }\end{array}$ & $\begin{array}{l}\text { Number of deaths } \\
(\%)\end{array}$ & $\begin{array}{l}\text { Relative odds of death } \\
(95 \% \mathrm{CI})^{\star}\end{array}$ & $\begin{array}{l}\text { Number of coronary } \\
\text { events (\%) }\end{array}$ & $\begin{array}{l}\text { Relative odds of coronary event } \\
(95 \% \mathrm{CI})^{*}\end{array}$ \\
\hline$<20.1$ & 467 & $88(19 \%)$ & 1.00 & $60(13 \%)$ & 1.00 \\
\hline 20.1 to 21.5 & 467 & $84(18 \%)$ & $0.94(0.67,1.32)$ & $78(17 \%)$ & $1.41(0.97,2.04)$ \\
\hline 21.6 to 22.7 & 467 & $83(18 \%)$ & $0.89(0.63,1.25)$ & $66(14 \%)$ & $1.12(0.76,1.63)$ \\
\hline 22.8 to 24.1 & 467 & $96(21 \%)$ & $1.03(0.74,1.45)$ & $83(18 \%)$ & $1.43(0.99,2.06)$ \\
\hline \multirow{2}{*}{$\geqslant 24.2-$} & 467 & $114(24 \%)$ & $1.29(0.93,1.79)$ & $95(20 \%)$ & $1.73(1.21,2.48)$ \\
\hline & & Likelihood ratio & $\chi^{2}=5.91 ; \mathrm{df}=4 ; \mathrm{p}=0.21$ & Likelihood ratio & $\chi^{2}=11.47 ; \mathrm{df}=4 ; \mathrm{p}=0.02$ \\
\hline
\end{tabular}

${ }^{\star}$ Relative odds adjusted for age, smoking habit and social class.

Table 2 Risk of death or a coronary event in the 14 years after screening examination in obese and non-obese men at 18 years of age

\begin{tabular}{|c|c|c|c|}
\hline \multirow[b]{2}{*}{ Body mass index } & \multirow[b]{2}{*}{ Total } & \multicolumn{2}{|l|}{ Number (\%) of men } \\
\hline & & Dead & With coronary event \\
\hline Less than 30 & 2294 & $451(20 \%)$ & $370(16 \%)$ \\
\hline 30 or more & 41 & $14(34 \%)$ & $12(29 \%)$ \\
\hline Relative odds adjusted for age, smoking habit and social class $(95 \% \mathrm{CI})$ & & $2.03(1.03,4.01)$ & $2.17(1.08,4.34)$ \\
\hline
\end{tabular}


Table 3. Risk of death or a coronary event in the 14 years after screening examination in fifths of distribution of change in body mass index from 18 years to recruitment

\begin{tabular}{|c|c|c|c|c|c|c|}
\hline $\begin{array}{l}\text { Fifth of change in body mass } \\
\text { index }\left(\mathrm{kg} / \mathrm{m}^{2}\right)\end{array}$ & $\begin{array}{l}\text { Mean weight change } \\
(\mathrm{kg})\end{array}$ & Total men & $\begin{array}{l}\text { Deaths } \\
n(\%)\end{array}$ & $\begin{array}{l}\text { Relative odds }{ }^{\star}+5 \\
(95 \% \text { CI })\end{array}$ & $\begin{array}{l}\text { Coronary events } \\
n(\%)\end{array}$ & $\begin{array}{l}\text { Relative odds }{ }^{\star} \neq \\
(95 \% \text { CI })\end{array}$ \\
\hline-10.5 to +0.86 & -3.5 & 466 & $123(26 \%)$ & 1.00 & $78(17 \%)$ & 1.00 \\
\hline 0.87 to 2.84 & 5.7 & 467 & $91(19 \%)$ & $0.77(0.56,1.06)$ & $83(18 \%)$ & $1.19(0.84,1.68)$ \\
\hline 2.85 to 4.53 & 10.8 & 467 & $79(17 \%)$ & $0.71(0.51,0.98)$ & $73(16 \%)$ & $1.09(0.76,1.56)$ \\
\hline 4.54 to 6.63 & 16.1 & 467 & $68(15 \%)$ & $0.58(0.41,0.82)$ & $65(14 \%)$ & $0.96(0.67,1.39)$ \\
\hline 6.64 to 25.4 & 27.0 & 466 & $103(22 \%)$ & $0.97(0.70,1.32)$ & $83(18 \%)$ & $1.26(0.89,1.80)$ \\
\hline
\end{tabular}

${ }^{\star}$ Relative odds adjusted for age, smoking habit and social class. †Trend $\chi^{2}=0.86, \mathrm{df}=1, \mathrm{p}=0.35$. Heterogeneity $\chi^{2}=13.5, \mathrm{df}=4, \mathrm{p}=0.009$. $\ddagger$ Trend $\chi^{2}=0.46, \mathrm{df}$ $=1, \mathrm{p}=0.50$. Heterogeneity $\chi^{2}=3.19, \mathrm{df}=4, \mathrm{p}=0.53$. \$Quadratic term significant.

Table 4 Mean increase in body mass index and weight gain in men (18 years to recruitment) by smoking category at recruitment

\begin{tabular}{llll}
\hline Smoking category & Number & $\begin{array}{l}\text { Mean increase in body mass } \\
\text { index }\left(\mathrm{kg} / \mathrm{m}^{2}\right)(95 \% \mathrm{CI})\end{array}$ & $\begin{array}{l}\text { Mean increase in weight } \\
(\mathrm{kg})(95 \% \mathrm{CI})\end{array}$ \\
\hline $\begin{array}{l}\text { Never smoked } \\
\text { Ex-smoker }\end{array}$ & 362 & $4.31(3.95,4.67)$ & $12.6(11.5,13.7)$ \\
$\begin{array}{l}\text { Pipe/cigar } \\
\text { Cigarettes daily }\end{array}$ & 675 & $4.66(4.38,4.94)$ & $13.8(13.0,14.6)$ \\
$\quad 250$ & $4.11(3.66,4.56)$ & $12.2(10.8,13.5)$ \\
$\quad 15-24$ & 324 & $2.46(2.04,2.89)$ & $7.1(5.9,8.4)$ \\
$25+$ & 414 & $2.85(2.50,3.20)$ & $8.3(7.3,9.3)$ \\
& 297 & $3.69(3.26,4.12)$ & $10.9(9.6,12.1)$ \\
\hline
\end{tabular}

Table 4 shows that smoking habit is strongly associated with weight change from 18 years of age to recruitment. Increases in body mass were greatest among ex-smokers and least among light smokers. The heaviest smokers, who experienced the greatest weight gain, were also the youngest age group and moderation in both smoking and calorie intake with advancing age may explain these findings.

Table 5 shows mean values for cardiovascular risk factors by weight gain categorised into fifths. Results are presented that allow for the range of values of each individual risk factor and are in SD units. Insulin and triglyceride (analysed on a logarithmic scale and converted to geometric means) show the largest increments at 0.24 and $0.20 \mathrm{SD}$ units for each fifth increment in body mass index.

\section{Discussion}

These data indicate that, for a cohort of men born between 1921 and 1937 and living in South Wales, body mass at 18 years had, for most men, no influence on subsequent mortality between the ages of 59 to 73 years. A significant relation was noted between the very few men classified as obese at 18 years of age with a body mass index of 30 or more units and subsequent incidence of ischaemic heart disease and death from any cause. Obesity among young men was rare before the second world war, only $41(1.8 \%)$ men falling into this category, resulting in very wide confidence intervals for odds ratios in this group. When using the wider classification of overweight at a body mass index of 25 units or above, no consistent gradient was found in mortality and incidence of ischaemic heart disease. However, when classified by fifths of body mass index at 18 years there was a non-significant $29 \%$ increase in the top fifth of the distribution (relative to the bottom fifth $\geqslant 24.2 \mathrm{~kg} / \mathrm{m}^{2}$ ). For coronary incidence the gradient was inconsistent but the relative odds were significantly increased by $73 \%$ in the top fifth.

It is recognised that this Welsh cohort will not include men who died between the ages of 18 years and recruitment to the study, and the effect of selective prior mortality of the overweight should be considered. We know of no such studies in the UK but in the Netherlands Hoffmans et $a l^{11}$ examined the fate of 18 year olds to the age of 50 years. In the Dutch cohort $0.8 \%$ of men had died of coronary disease and $1 \%$ from cancer by age 50 years. The mean body mass index of coronary cases and controls was similar (21.0 (SD 2.0) and 20.8 (SD $1.8 \mathrm{~kg} / \mathrm{m}^{2}$ respectively) in the Dutch study and therefore selective effects are unlikely to have biased the results of the present study.

In our cohort, in common with the majority of other western populations, ${ }^{12}$ most men gained weight until middle age. By age at entry into the study the achieved body weight was stable, with a small decline in the oldest age group of men examined. The rounding of weights at 18 years to the nearest half stone may have resulted in some misclassification of body mass index at 18 years and consequently may have slightly diminished our ability to detect associations with mortality and incident ischaemic heart disease to give a positive finding; but it seems unlikely that any spurious association would be generated.

The findings in this population sample of men are in broad agreement with those of the British survey of heights and weights of adults undertaken in $1980 .{ }^{13}$ This study found that the Welsh sample of men contained one of the highest proportions of overweight men.

Table 5 Change in body mass index in men (18 years to recruitment) and mean levels of cardiovascular risk factors at recruitment

\begin{tabular}{|c|c|c|c|c|c|c|c|}
\hline Fifth of change in body mass index $\left(\mathrm{kg} / \mathrm{m}^{2}\right)$ & $\begin{array}{l}\text { Insulin* } \\
\text { (geometric mean) } \\
\text { (IU/l) }\end{array}$ & $\begin{array}{l}\text { Total triglyceride } \\
\text { (geometric mean) } \\
\text { (mmolll) }\end{array}$ & $\begin{array}{l}\text { Glucose } e^{\star} t \\
(m m o l / l)\end{array}$ & $\begin{array}{l}\text { Diastolic blood } \\
\text { pressure } \\
(\mathrm{mm} \mathrm{Hg})\end{array}$ & $\begin{array}{l}\text { Systolic blood } \\
\text { pressuret } \\
\text { (mm } \mathrm{Hg} \text { ) }\end{array}$ & $\begin{array}{l}\text { HDL } \\
\text { cholesterol } \\
\text { (mmolll) }\end{array}$ & $\begin{array}{l}\text { Total } \\
\text { cholesterolf } \\
\text { (mmolll) }\end{array}$ \\
\hline-10.5 to +0.86 & 4.02 & 1.23 & 4.70 & 85 & 135 & 1.19 & 6.01 \\
\hline 0.87 to 2.84 & 4.74 & 1.42 & 4.74 & 87 & 141 & 1.13 & 6.24 \\
\hline 2.85 to 4.53 & 5.80 & 1.55 & 4.86 & 89 & 141 & 1.12 & 6.26 \\
\hline 4.54 to 6.63 & 6.43 & 1.76 & 4.85 & 89 & 142 & 1.09 & 6.32 \\
\hline 6.64 to 25.4 & 8.55 & 1.97 & 5.08 & 93 & 145 & 1.05 & 6.26 \\
\hline $\begin{array}{l}\text { Mean increase per fifth of change in body mass index, } \\
\text { expressed in SD units for each risk factor }\end{array}$ & 0.24 & 0.20 & 0.15 & 0.14 & 0.11 & -0.10 & 0.05 \\
\hline
\end{tabular}

All between group comparisons were highly significant $\left(\mathrm{p}<0.001\right.$ by one way analysis of variance) as were tests for linear trend. ${ }^{\star}$ Diabetics $($ defined by clinical history or by glucose $\geqslant 7.8 \mathrm{mmol} / \mathrm{l}$ ) excluded from insulin and glucose analyses. †Evidence of departure from linear trend $(\mathrm{p}<0.05)$. 
Average weight gain in older men in Britain, estimated from the age of 21 years to middle age was $7.6 \mathrm{~kg}$ compared with $11.2 \mathrm{~kg}$ in this study.

The amount of weight gain was strongly associated with smoking habit, smokers gaining only $66 \%$ of the weight gained by those who had never smoked. We also fitted statistical interactions to the logistic model to check if the effects on mortality and cardiovascular morbidity of increasing body mass index between 18 years and recruitment varied with smoking habit at recruitment.

Highest mortality was shown by those who lost weight. Although the size of this effect was slightly reduced by excluding deaths early in the follow up at one year, two years, three years and five years the pattern of mortality was very similar, with the lowest mortality in men who had gained $16.1 \mathrm{~kg}$ on average. Shaper et al suggest that body mass index should ideally be maintained at $22-23.9 \mathrm{~kg} / \mathrm{m}^{2}$ during adult life, but a review of 11 population studies that includes several studies with self reported weights in young adulthood suggests that some degree of weight gain in adulthood is associated with lower all cause mortality. ${ }^{14}$

However, the impact of weight gain on some possible cardiovascular risk factors can be clearly seen (table 5), particularly for insulin and triglyceride. The impact of increases in these variables may be relatively weak in men dying between the ages of 45 to 73 years of age as we have previously reported ${ }^{9}$ and the effects of weight gain may be stronger in an older age group with a longer period of follow up. Body mass index at 18 years showed no consistent relations with the cardiovascular risk factors shown in table 5, while body mass index at screening showed a very similar pattern of trends to that shown by weight gain. The influence of weight gain on cardiovascular mortality has been reported for a 20 year follow up in the Gotenberg Study; ${ }^{15}$ lowest mortality from coronary heart disease was found in men with stable weight during follow up $( \pm 4 \%)$, and men with greater weight gain showed a significantly increased risk of death from coronary disease. Duration of follow up may be particularly important for adequate assessment of the impact of overweight. For example in a study of 18244 Chinese men aged aged 45-64 years followed up for 6.7 years on average, ${ }^{16}$ cardiovascular mortality was significantly increased only in the upper fifth of the distribution of body mass $\left(\geqslant 26.0 \mathrm{~kg} / \mathrm{m}^{2}\right)$ in which a twofold increase in cardiovascular mortality occurred in lifelong non-smokers. In an Italian study $^{17}$ of over 62000 men and women followed up for six years the minimum risk of death was found in middle aged men with a body mass index of $29 \mathrm{~kg} / \mathrm{m}^{2}$. A review of prospective studies ${ }^{18}$ found that minimum risk occurred in non-smoking 50 year old men followed up for 30 years with body mass index between 23 and $28 \mathrm{~kg} / \mathrm{m}^{2}$.
Future British, north American and western European cohorts will differ from the present cohort in the proportion of smokers, only $16 \%$ of our cohort having never smoked; current cohorts of young adults typically contain $60 \%$ of non-smokers. ${ }^{1}$ On balance the evidence suggests that excess mortality caused by smoking greatly outweighs the effect of being overweight. However, in the youngest age group of the English Health Survey 18-24 years the prevalence of clinical obesity has risen to $5 \%{ }^{1}$ and this group are clearly at increased risk. Both declining levels of physical activity and changing dietary patterns have been suggested to contribute to this trend ${ }^{7}$ and a changing spectrum of cardiovascular risk factors may have implications for the trends and presentation of future cardiovascular disease. New studies in larger and younger cohorts will be required to adequately examine the health consequences of being overweight.

The authors thank the staff of the former MRC Epidemiology Unit (S Wales) and the subjects who participated in the study.

Funding: Medical Research Council.

Conflicts of interest: none.

1 Department of Health. Health Survey for England 1994. London: HMSO, 1996.

2 Shaper AG, Wannamethee SG, Walker M. Defining a healthy body weight for middle-aged men: implications for the prevention of coronary heart disease, stroke and the prevention of coronary heart disease,
diabetes mellitus. BMF 1997;314:1311-17.

3 Kushner RF. Body weight and mortality. Nutr Rev 1993;51: 127-36.

4 Byers T. Body weight and mortality. $N$ Engl $f \mathrm{Med}$ 1995;333:723-4.

5 Tokunaga K, Matsuzawa Y, Kotani K, et al. Ideal body weight estimated from the body mass index with the lowest morbidity. Int F Obes 1991;15:1-5.

6 Garrison RJ, Kannel WB. A new approach for estimating healthy body weights. Int $\mathcal{F}$ Obes 1993;17:417-23.

7 Prentice AM, Jebb SA. Obesity in Britain: gluttony or sloth: BMF 1995;311:437-9.

8 Tunstall-Pedoe H. Contour control, survival, and quality of life. Ideal body weight is far lower than average. $B M \mathcal{F} 1997$; 314:1291-2.

9 Yarnell JWG, Patterson CC, Bainton D, et al. Is metabolic syndrome a discrete entity in the general population? Evidence from the Caerphilly and Speedwell population Evidence from the Caerphilly and
studies. Heart 1998;79:248-52..

10 Yarnell JWG, Pickering JE, Elwood PC, et al. Does non-diabetic hyperglycemia predict future IHD? Evidence from the Caerphilly and Speedwell Studies. I Clin Epidemiol 1994;47:383-8.

11 Hoffmans MDAF, Kromhout D, de Lezenne Coulander C. Body mass index at the age of 18 and its effects on 32-year mortality from coronary heart disease and cancer: a nested case-control study among the entire 1932 Dutch male birth cohort. F Clin Epidemiol 1989;42:513-20.

12 Department of Health. Obesity. Reversing the problem of obesity in England. A report from the nutrition and physical activity task force. London: HMSO, 1995.

13 Knight I. The heights and weights of adults in Great Britain. London: HMSO, 1984.

14 Andres R, Muller DC, Sorkin JD. Long-term effects of change in body weight on all-cause mortality: a review. Ann Intern Med 1993;119:737-43.

15 Rosengren A, Wedel H, Wilhelmsen L. Body weight and weight gain during adult life in men in relation to coronary Eur Heart $\mathcal{F}$ 1999;20:269-77.

16 Yuan J-M, Ross RK, Gao Y-T, et al. Body weight and mortality: a prospective evaluation in a cohort of middleaged men in Shanghai, China. Int F Epidemiol 1998;27:82432 .

17 Seccareccia F, Scanga M, Lanti M, et al. Role of body mass index in the prediction of all cause mortality in over 62,000 men and women. The Italian RIFLE Pooling Project. $\mathcal{7}$ Epidemiol Community Health 1998;52:20-6.

18 Troiano RP, Frongillo EA, Sobal J, et al. The relationship between body weight and mortality: a quantitative analysis of combined information from existing studies. Int 7 Obes 1996;20:63-75. 